\begin{tabular}{|l|cc|c|}
\hline & $\begin{array}{r}\text { PORT-SAID ENGINEERING RESEARCH JOURNAL } \\
\text { Faculty of Engineering - Port Said University }\end{array}$ \\
Volume 23 & No. 1 & March $2019 \quad$ pp: $83: 93$
\end{tabular}

\title{
A Numerical Study of the Effect of Endwall Injection Blowing Ratio on a High Pressure Turbine Cascade Performance
}

\author{
Alam El-Din, A. M. ${ }^{l}$, El-Ghandour, M. E. ${ }^{2}$, Hassan, Y. K. ${ }^{3}$
}

\begin{abstract}
The aerodynamics of the flow in a turbine stage is complex and still the subject of many ongoing researches. The secondary flow is the major source of aerodynamic losses in a turbine stage. Fluid injection from the endwall is used to improve the aerodynamic performance. For the current study, the change of injection blowing ratio has been investigated as an effective way to increase turbine efficiency by mitigating the strength of vortices. The interaction between the main flow and the injection flow from flat endwall is analyzed by numerical simulation. Five endwall injection holes were placed near the blade suction side on a typical flat blade cascade with two injection blowing ratios. In these cases, each hole has the same blowing ratio. Furthermore, two other test cases (mixing blowing ratio) in which every hole has its own blowing ratio independent of other holes. The new injection arrangements techniques have proved its effectiveness in increasing blade loading by $1.85 \%$ more than baseline test case blade loading. In addition to suppression flow losses by $2.1 \%$ less than baseline test case losses.
\end{abstract}

\section{INTRODUCTION}

The secondary flow in high pressure turbine represents a major challenge to the turbine designers to increase the turbine efficiency. Basically, primary or uniform flow is an idealized two-dimensional form of the streamlines between the suction and pressure surfaces of a turbine blade passage. Flow deviations from the idealized form have come to be called "secondary", even though their presence may constitute whole regions of the turbine blade passage flow field. Secondary flows include endwall boundary layers, their separation, and other portions of the primary flow influenced by three-dimensional effects. During the last two decades, mastery of secondary flow phenomenon has become critical to modern turbine designs [1].

The physics behind formation of the passage vortex is described in details by Gregory-Smith and Okan [2]. When a sheared flow such as a boundary layer forced around a turn the slower moving fluid follows a tighter radius of curvature, leading to a tangential flow across the passage. Then, in order to preserve continuity, a vertical flow is formed. Longston [3] presented a classic secondary flow model based on detail experimental measurements in a turbine cascade [4], and also presented that the secondary flow in turbine passage consisted of three kinds of flow components such as the passage vortex, the corner vortex and the horse shoe vortex splitting into a pressure side leg and a suction side leg (and tip leakage vortex in rotor blade passage). In fact, these vortical flows originate from the leading edge of the airfoil by rolling up of the boundary layer, and transform to horseshoe vortex when it spreads to the

\footnotetext{
Professor, Mech. Power Dept., Faculty of Engineering, Port Said University, Port Said, Egypt, Email: atefalameldin@yahoo.com 2 Lecturer, Mech. Power Dept., Faculty of Engineering, Port Said University, Port Said, Egypt, Email: mghandour@eng.psu.edu.eg 3 Researcher, Mech. Power Dept., Faculty of Engineering, Port Said University, Port Said, Egypt, Email: yasserkamal@eng.psu.edu.eg
}

whole passage. The migration and development of the vortex through the entire passage indicate their importance in the overall aerodynamic losses.

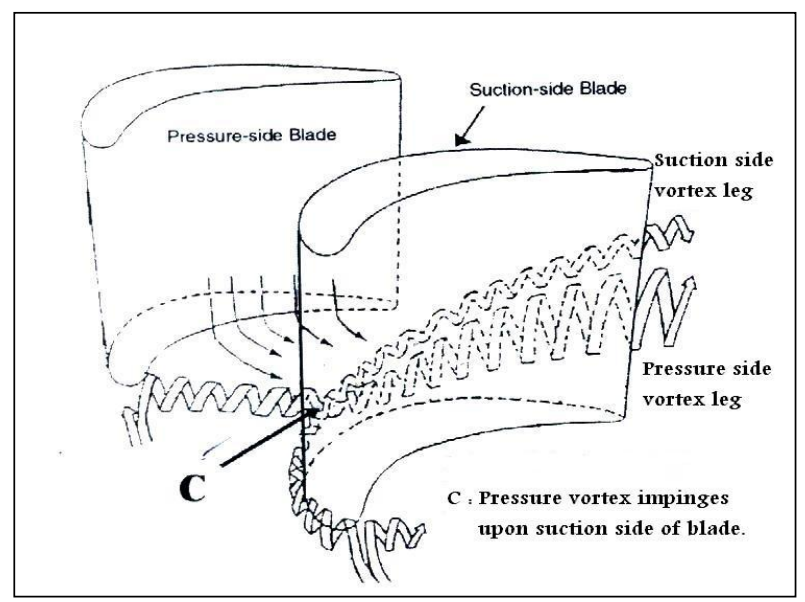

Fig. 1: Schematic of horseshoe vortex impinging upon suction-side blade [18]

When the fluid boundary layer approaches the blade leading edge, it is subjected to an adverse pressure gradient and starts to roll up to form a horse shoe vortex with two legs [18] as shown in Fig. 1 , one to pressure side (move away from the pressure surface and toward the suction surface of the adjacent blade to be the major component of the passage vortex) and the other to suction side (travels along the suction surface toward the trailing edge), it moves away from the endwall toward the midspan and downstream to the separation bubble and hence increase the losses [5].

Secondary flow controlling methods according to most of previous studies are mainly classified to two categories, the first category is dealing with structural 
measures in blade or endwall geometry and the second category is dealing with injection or suction of air directly to the flow passage.

Turbine blade loading, $(L)$, is the main output of gas turbine Engine which is the main reason for turbine disk rotation then introducing a flow or mechanical power to service a specific part of the engine. The blade loading or lift (equation 1) that provides work on the turbine shaft is determined for blade cross section at certain span distance based on the area of integration of local static pressure at every point on blade surface cross section chordwisely from Leading edge to trailing edge [6].

$$
\mathcal{L}=\frac{1}{2} \rho A v^{2} C_{L}
$$

The blowing ratio $M_{h \text {-inlet }}$ (equation 2) is the ratio that an idealized loss free injection hole would have when injecting to inlet conditions [7].

$$
M_{h-\text { inlet }}=\frac{\left(\dot{\mathrm{m}}_{\text {inj }} / A_{\text {holes }}\right)}{\rho_{\infty} \cdot U_{\infty}}
$$

The compound angle of injection hole has two injection angles as shown in Fig. 2 [8]. In the compound angle orientation system, the injected flow is injected with spanwise, chorwise and pitchwise momentum components.

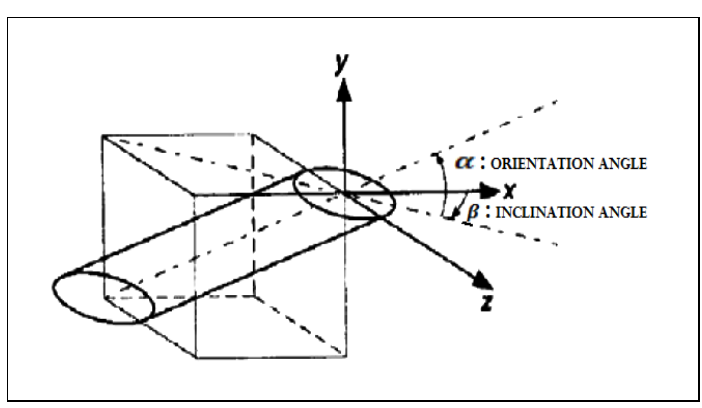

Fig. 2: Injection hole compound angle [8]

The blowing ratio $\left(\beta_{h}\right)$ is defined as the angle between the injection vector and its projection on the $\mathrm{x}$ $\mathrm{z}$ plane, whereas the orientation angle $\left(\alpha_{h}\right)$ is defined as the angle between the streamwise direction and the projection of the injection vector on the $\mathrm{x}-\mathrm{y}$ plane.

Abdullah et al. [9] showed the injection flow as a potential solution to provide a cooling protection at the end wall region of a turbine blade arrangement. Two mass flow rates of the injection flow have been considered. Their investigation indicates no influence of density ratio on aerodynamic losses of the purge flow however small improvement in terms of area average film cooling effectiveness have been observed at a higher density ratio value.

Tyler et al. [10] introduced a numerical investigation of the flow development of injection flow injected from 6 injected plenums inside the turbine. The blowing ratio and density ratio are varied to understand the impact of these parameters on the passage vortex and film cooling effectiveness, in the near endwall region where the passage vortex effects are most prominent, by varying the blowing ratio. The passage vortex removes injection flow at the same rate regardless of the blowing ratio and due to the increased momentum of the injection flow with higher blowing ratio, the injection flow is going to protect the blade surface more, downstream of the injection holes.

\section{MODEL STUDY}

This numerical study is carried out to establish the effect of mixing blowing ratios of endwall injection on a high pressure turbine cascade performance through flow channel between two consecutives blades by simulating a large scale transonic turbine blade cascade. Detailed measurements, made by Ashlie et al. [11], are used for validation of the CFD results by using the same inlet flow conditions and existing blade geometry. The test blade is a scaled rotor tip section of the GE Energy Efficient Engine (EEE) design [12], that has an axial chord of $130.0 \mathrm{~mm}$, a blade pitch of $130.0 \mathrm{~mm}$, a span of $152.4 \mathrm{~mm}$, and a design-intent inlet flow angle of $\beta_{1, \text { des }}=+29.7^{\circ}$ with inlet conditions as shown in Table 1 . This blade geometry was considered to be a good test case because direct comparisons could be made between data obtained by Ashlie et al experimental results and the current study CFD results.

Table 1: Experimental inlet conditions, Ashlie et al. [11]

\begin{tabular}{|c|c|}
\hline \multicolumn{2}{|c|}{ Inlet conditions } \\
\hline$\beta_{1}$ Relative flow angle & $38.8^{\circ}$ \\
\hline$i$ Incidence angle, $i=\beta_{1}-\beta_{1, \text { des }}$ & $+9.1^{\circ}$ \\
\hline$R e_{C x, 1}$ & 685,300 \\
\hline PR Pressure Ratio, $\mathrm{PR}=P_{t 1} / \overline{P_{2}}$ & 1.4472 \\
\hline$M_{2, i}$ Mach number & 0.746 \\
\hline Est. $\delta_{1}$ Boundary layer thickness, $\mathrm{m}$ & 0.0326 \\
\hline
\end{tabular}

The injection location is selected at blade aft suction side (the region of separation), the selection of these particular locations is based to higher blade loading results and relatively low losses results in experiment test study Alam El-Din et al. [13].

\section{MATHEMATICAL MODEL}

The numerical code, used in this study, is ANSYS Fluent (version 14.5) [14]. The mathematical model was implemented into ANSYS Fluent code based on the finite volume method to discretize the three-dimensional compressible Naveir-Stockes equations. The hexahedral structured multi-block grids with total of 82 blocks structured mesh were designed. The blade and endwall mesh inflations are refined near walls to get the velocity gradient in the secondary layer. A steady-state code and only one blade passage was modeled. The code was running in a parallel mode with a four-thread job density based solver.

\subsection{CFD Governing Equations}

The numerical simulation of compressible flows is based on the solution of the conditionally-averaged Navier- Stokes equations completed by a turbulence model and by a model of the laminar/turbulent 
transition. In this solver, the 2nd-order central differencing is applied for viscous numerical fluxes. The equations of finite volume method and turbulence model and its discretization are described in ANSYS FLUENT Theory guide (ver. 14.5). And the basic conservative equations are described by Versteeg and Malalaskera [15].

\subsection{Computational Domain and Mesh}

The geometry of the blade cascade is created by ANSYS Design Modeler (14.5 version), as illustrated by Fig. 3. The computational domain for the study of the three-dimensional injection flow to linear cascade flow is consisted of one pitch endwall with a single blade periodicity channel. The blade model is $2 \mathrm{D}$ with the same profile in the span direction and extended from 1.0 $\mathrm{C}_{a x}$ upstream of the leading edge to $2.0 \quad \mathrm{C}_{a x}$ downstream of the trailing edge, in the same manner as Wan et al. [16]. The computational domain for a single pitch of the GE Energy Efficient Engine (EEE) blade is shown in Fig. 3.

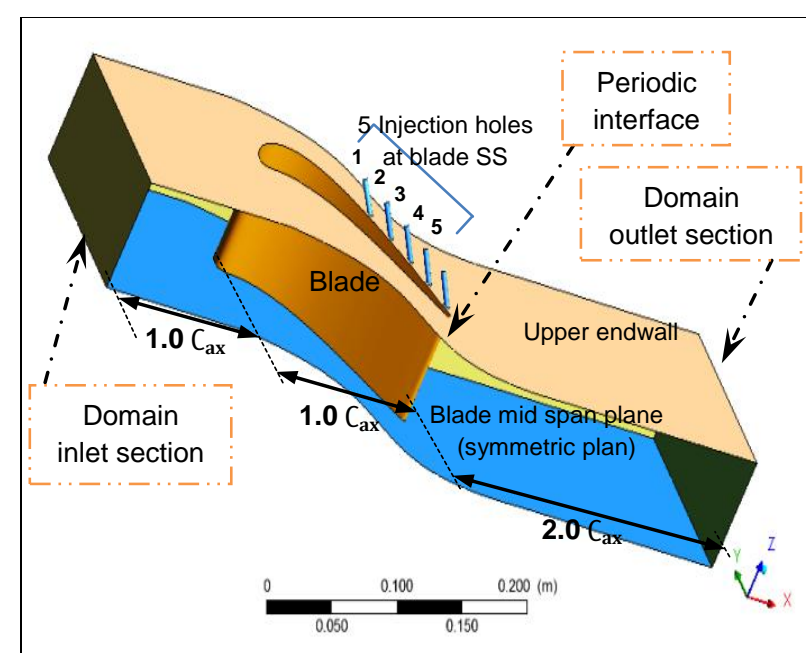

Fig. 3: The flow domain geometry

According to the law of the wall of Theodore von Kármán [17], which states "the average velocity of a turbulent flow at a certain point is proportional to the logarithm of the distance from that point to the wall boundary of the fluid region", a non-dimensional wall-

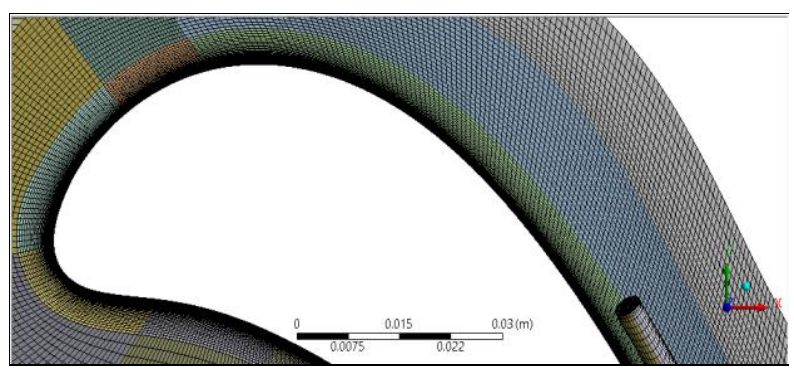

Fig. 4: The blade wall elements inflation

-distance for a wall-bounded flow, y plus $\left(y^{+}\right)$, can be calculated by Fluent to precise the wall effect on the flow behavior. The density of mesh cells is increased in the vicinity of the blade wall with elements inflation and also at endwall surface with elements inflation and spanwise distribution as shown in Fig. 4 and Fig. 5 respectively.

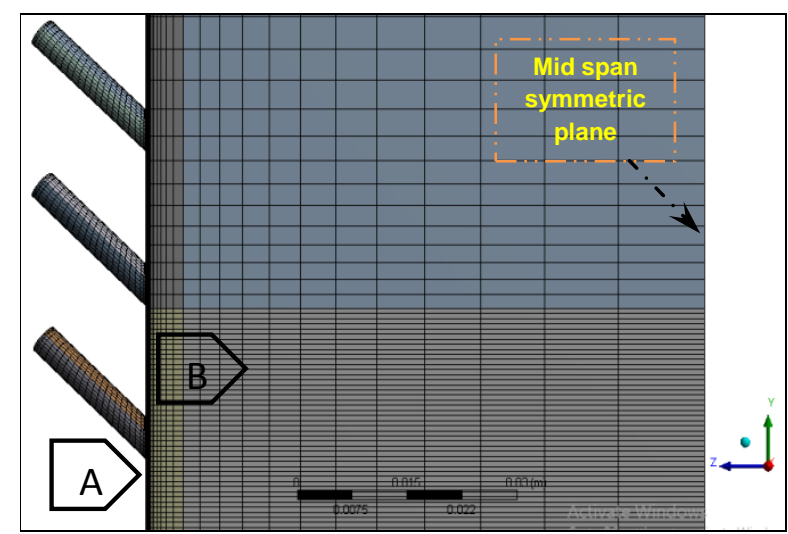

Fig. 5: Meshing, (A) Endwall inflation (B) Spanwise distribution

The initial domain grid elements were $1,816,233$ elements with 641335 nodes, which include 20 edge sizings with different values. The element size is $2 \mathrm{x}$ $10^{-3} \mathrm{~m}$. After a series of tests and adjustments, the final adopted 3D wall-function mesh for the entire computational domain, have a total of 2.2 million of hexahedral cells.

An assumption of flow characteristics symmetry upper and lower blade mid span plane, is existing. This assumption saved the solution time cost as the computational model domain is only considered from blade mid span to blade cascade endwall.

\subsection{Turbulence Models Sensitivity Study}

A turbulence models sensitivity study was made to find the best accurate turbulence model which can predict a stable solution with minimum errors comparing to experimental results. Four turbulence models were tested with the same grid elements 2.2 million cells as follows;

1-The standard SST (Shear Stress Transport) k- $\omega$,

2-The one-Equation Spalart-Allmaras,

3-The two-Equation Realizable $\mathrm{k}-\varepsilon$ and

4-The SST (Shear Stress Transport) Transition

The turbulence models check has been carried out to compare the result of two important flow performance factors with the experimental result as follows;

1-Total Pressure Loss Coefficient $\omega$ and

2-Total pressure coefficient $C_{P t}$

\subsubsection{Turbulence Models Check for Total Pressure Loss Coefficient $\omega$}

The total pressure loss coefficient, $\omega$, of the experimental result, with the application of the same boundary conditions, is computing using Equation (3) [11]. As shown in Fig. 6, the nearest predicted result to the experimental result is counting by Spalart-Allmaras model with a tolerance of experiment result is $+1.9 \mathrm{x}$ $10^{-4} \%$. In the other side, the SST Transition Model 
calculates the highest tolerance of experiment result is $0.12 \%$.

$$
\omega=\frac{\left(P_{t 1}-\overline{P_{t 2}}\right)}{\left(P_{t 1}-\overline{P_{2}}\right)}
$$

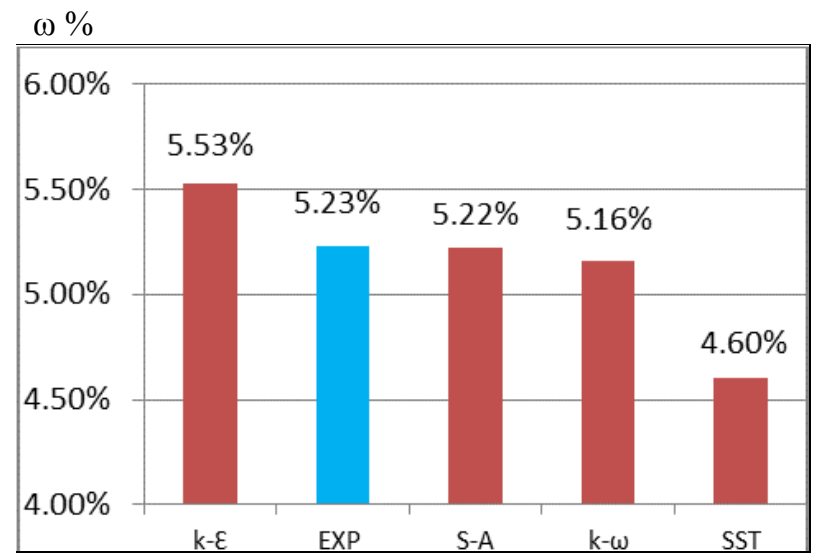

Fig. 6: Loss coefficient $\omega \%$ at exit section for different turbulence models and the experiment results

\subsubsection{Turbulence Models Check for Total Pressure Coefficient $C_{P t}$}

The total pressure coefficient, $C_{P t}$, from experimental result, can be calculated from Equation (4) [11]. Fig. $V$ represents, in the $\mathrm{x}$ axis, $\mathrm{y}$ - coordinate of blade cascade in pitch direction ratio to blade pitch and the total pressure coefficient distribution [11]. It is generated, by comparing the experiment result to the numerical results of the different applicable turbulence models with the same boundary conditions of the experiment study.

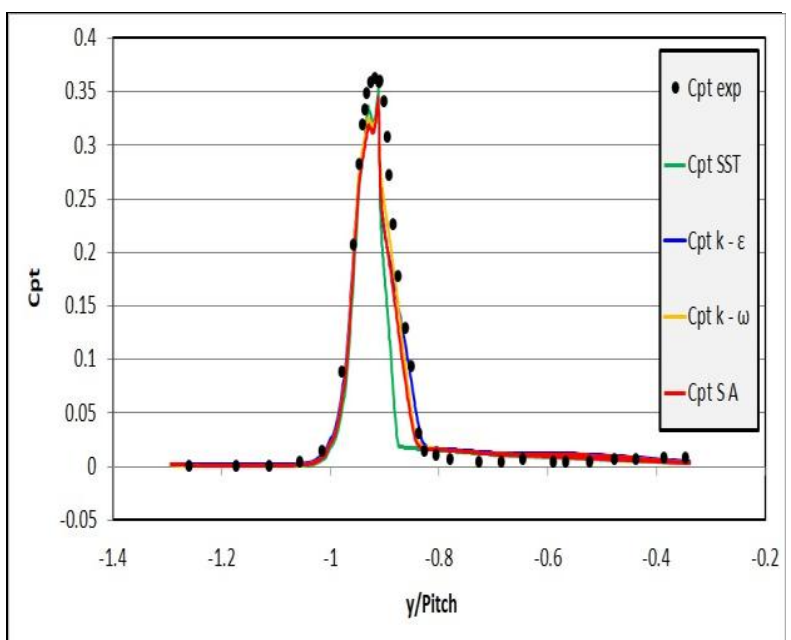

Fig. 7: Total pressure coefficient $C_{P t}$ with $+9.1^{\circ}$ incidence angles with different turbulence models results

$$
\mathbf{C}_{\mathbf{P t}}=\frac{\left(\mathbf{P}_{\mathbf{t} 1}-\mathbf{P}_{\mathbf{t}}\right)}{\left(\mathbf{P}_{\mathbf{t} 1}-\overline{\mathbf{P}_{2}}\right)}
$$

The calculations show that, the nearest predicted result to the experiment result is that with the Spalart-Allmaras model because of a good matching between its line plot with the experiment result line plot. In the other side, the SST Transition Model calculates the highest deviated line of experiment result line plot.
According to the previous study, The SpalartAllmaras model has been selected for CFD calculations in the progress of the current study.

\subsection{Grid Dependency Study}

In order to choose the suitable mesh, three mesh densities were tested with test case No. as follows:

1- 0.56 million cells, coarse grid

2- 2.2 million cells, medium grid

3- 5.1 million cells, fine grid

Simulations were carried out for the total pressure loss coefficient, $\omega$, because of its importance to the present study. The difference in loss coefficient, $\omega$ is varied by $12.18 \%$ for the coarse grid ( 0.56 million cells) and $8.96 \%$ for the medium grid $(2.2 \mathrm{M})$, relative to the most refined grid. The mass-averaged total pressure is presented at a plane located at1.086 $C_{a x}$ downstream blade leading edge. The loss coefficient, $\omega$, was estimated for the three grids and depicted in Fig. 8. It shows that the loss coefficient, $\omega$ is converged with increasing the grid points. Therefore, the medium grid was selected in this study. This would be enough to capture details of the flow characteristics and based on these results, the medium grid size is considered to be sufficient for flow field predictions.

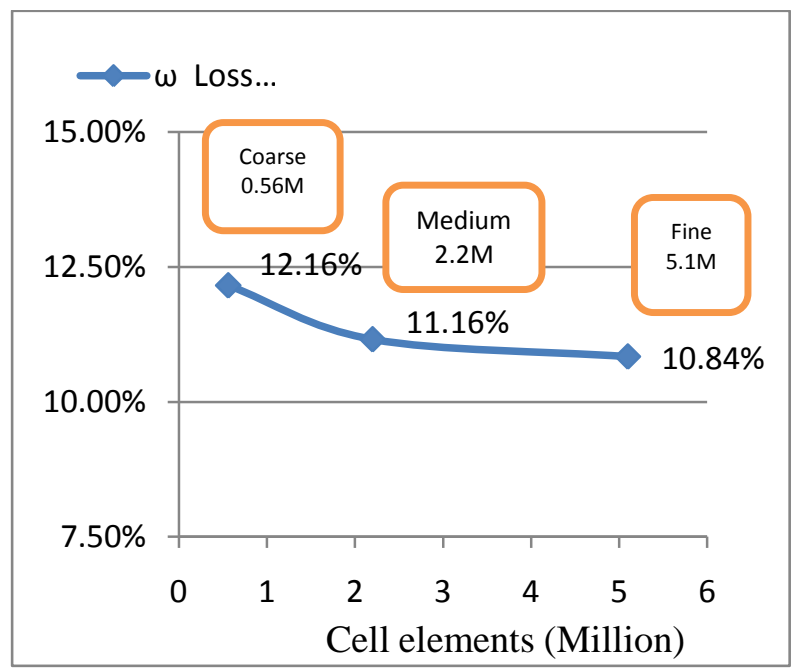

Fig. 8: Grid Dependency study for Coarse, Medium and Fine Grid

\subsection{Solver Validation}

Validation data is very critical to gain confidence in the calculated results. The experimental result of Ashlie et al. [11], was used for solver validation, the vertical axis is the static pressure coefficient, $C_{P S}$ whereas the horizontal axis is blade axial location to blade axial chord $\mathrm{x} / C_{x}$ at the blade mid span. The static pressure coefficient, $C_{P S}$, is calculated by Equation (5) [11] as follows;

$$
C_{P S}=\frac{\left(P-\overline{P_{2}}\right)}{\left(P_{t 1}-\overline{P_{2}}\right)}
$$

Spalart-Allmaras turbulence model results show reasonable agreement with the experimental results as shown in Fig. (9), except for some differences on the 
suction side and near the trailing edge, which is believed to be due to the sensitivity of the turbulence model and grid topology.

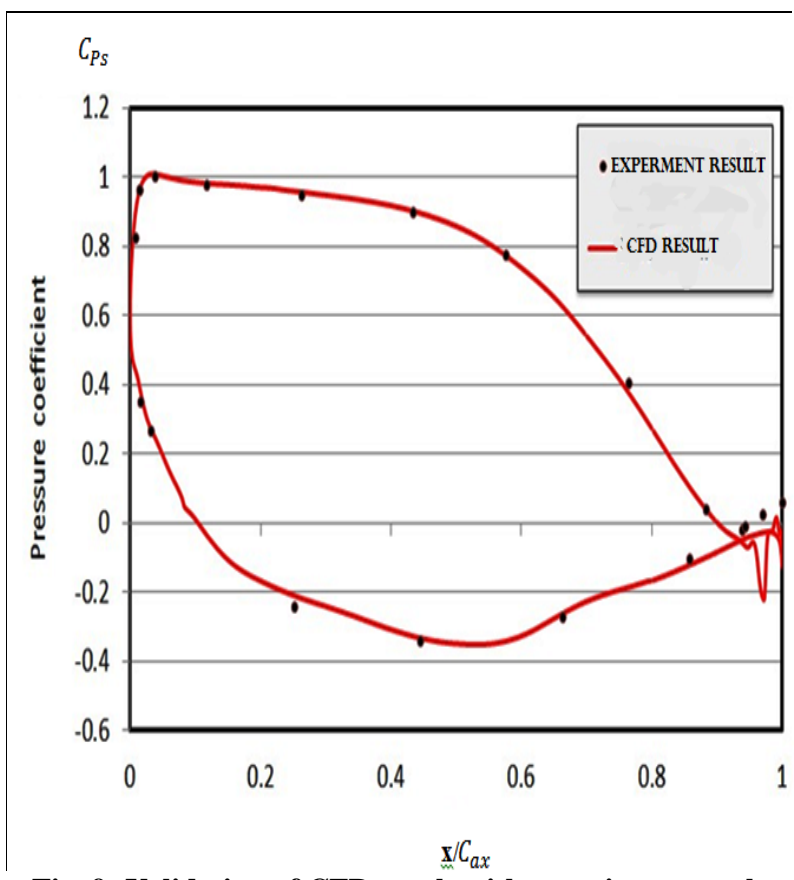

Fig. 9: Validation of CFD result with experiment result [11] of static pressure coefficient, $C_{P s}$ at the blade mid span

Maximum $y^{+}$of 3.3 occurs at endwall with the blade SS corner. While no valuable change in wall $y^{+}$ on blade pressure side (PS) after injection application compared to the base line. Moreover, the wall $y^{+}$does not exceed a value of 22 on the blade cascade endwall. Spalart-Allmaras turbulence model (The current test cases turbulence model) has been extended within ANSYS FLUENT with $y^{+}$values in the buffer layer $\left(1<y^{+}<30\right)$ [14]. The calculated $y^{+}$values emphasizes that, all 9 test cases were carried out with a stable solution by fluent calculations of flow parameters near walls of the calculation domain. For further details, see Alam El-Din et al. [21].

\section{RESULTS DISCUSSION}

The injection process is carried out via a set of five holes. There are two methods of injection. In the first one, all the five holes have the same mass flow rate (MFR). However, in the second method, every injection hole has different mass flow rate (MFR) as shown in Table 2.

Table 2: Tested blowing ratios $M_{h-\text { inlet }}$

\begin{tabular}{|c|c|c|}
\hline Case No. & \multicolumn{2}{|c|}{ blowing ratios $M_{h \text {-inlet }}$} \\
\hline 1 & \multirow{2}{*}{$\begin{array}{c}\text { All five injection holes } \\
\text { have the mass flow rate }\end{array}$} & 0.6 \\
& (MFR) - method (1) & 1.2 \\
\hline 3 & $\begin{array}{c}\text { Different mass flow rate } \\
\text { (MFR) for each injection } \\
\end{array}$ & $\begin{array}{c}0.552 \\
\text { (mixing) }\end{array}$ \\
\hline 4 & $\begin{array}{c}0.312 \\
\text { hole - (mixing) }\end{array}$ \\
\hline
\end{tabular}

Four test cases are presented to investigate the effect of changing the injection hole blowing ratio on flow performance with injection location at blade SS as shown in Fig. 3 and injection inclination angle, $\beta_{h}=45^{\circ}$. Meanwhile, the injection holes orientation angles $\left(\alpha_{h}\right)$ for each test case location were selected to obtain flow direction matching between the injection flow and main passage flow and this to avoid disturbance or increasing losses of main flow. The values of each hole MFR and orientation angles are shown in Table 3 for all test cases.

Table (3) Injection hole configuration and inlet conditions

\begin{tabular}{|c|c|c|c|c|c|}
\hline \multicolumn{2}{|c|}{$M_{h-\text { inlet }}=$} & 0.6 & 1.2 & 0.552 & 0.312 \\
\hline \multirow{5}{*}{$\underset{(\mathbf{m m})}{\mathbf{X}}$} & $x_{1}$ & 93 & 93 & 93 & 55 \\
\hline & $x_{2}$ & 104 & 104 & 104 & 76 \\
\hline & $x_{3}$ & 114 & 114 & 114 & 93 \\
\hline & $x_{4}$ & 122.9 & 122.9 & 122.9 & 108 \\
\hline & $x_{5}$ & 131.2 & 131.2 & 131.2 & 126 \\
\hline \multirow{5}{*}{$\underset{(\mathbf{m m})}{\mathbf{Y}}$} & $y_{1}$ & 0 & 0 & 0 & 45 \\
\hline & $y_{2}$ & -20 & -20 & -20 & 24.8 \\
\hline & $y_{3}$ & -40 & -40 & -40 & 1 \\
\hline & $y_{4}$ & -60 & -60 & -60 & -20 \\
\hline & $y_{5}$ & -80 & -80 & -80 & -50 \\
\hline \multirow{5}{*}{$\underset{(\mathbf{m m})}{\mathbf{Z}}$} & $z_{1}$ & 76.2 & 76.2 & 76.2 & 76.2 \\
\hline & $z_{2}$ & 76.2 & 76.2 & 76.2 & 76.2 \\
\hline & $z_{3}$ & 76.2 & 76.2 & 76.2 & 76.2 \\
\hline & $z_{4}$ & 76.2 & 76.2 & 76.2 & 76.2 \\
\hline & $Z_{5}$ & 76.2 & 76.2 & 76.2 & 76.2 \\
\hline \multirow{5}{*}{$\boldsymbol{\beta}_{h}{ }^{\circ}$} & $\beta_{h 1}$ & 45 & 45 & 45 & 75 \\
\hline & $\beta_{h 2}$ & 45 & 45 & 45 & 75 \\
\hline & $\beta_{h 3}$ & 45 & 45 & 45 & 67.5 \\
\hline & $\beta_{h 4}$ & 45 & 45 & 45 & 60 \\
\hline & $\beta_{h 5}$ & 45 & 45 & 45 & 60 \\
\hline \multirow{5}{*}{$\alpha_{h}^{\circ}$} & $\alpha_{h 1}$ & -58 & -58 & -58 & -28.5 \\
\hline & $\alpha_{h 2}$ & -62.5 & -62.5 & -62.5 & -52 \\
\hline & $\alpha_{h 3}$ & -63.8 & -63.8 & -63.8 & -56.7 \\
\hline & $\alpha_{h 4}$ & -66.5 & -66.5 & -66.5 & -60 \\
\hline & $\alpha_{h 5}$ & -67 & -67 & -67 & -63 \\
\hline \multirow{5}{*}{$\underset{(\mathrm{mm})}{\boldsymbol{D}_{\boldsymbol{h}}}$} & $D_{h 1}$ & 4 & 4 & 4 & 3.5 \\
\hline & $D_{h 2}$ & 4 & 4 & 4 & 3.5 \\
\hline & $D_{h 3}$ & 4 & 4 & 4 & 3.5 \\
\hline & $D_{h 4}$ & 4 & 4 & 4 & 3.5 \\
\hline & $D_{h 5}$ & 4 & 4 & 4 & 3.5 \\
\hline \multirow{5}{*}{$\begin{array}{c}M F R_{h} \\
(\mathrm{~g} / \mathbf{s})\end{array}$} & $M F R$ & 1 & 2 & 1.5 & 0.75 \\
\hline & $M F R$ & 1 & 2 & 1.2 & 0.5 \\
\hline & $M F R$ & 1 & 2 & 0.9 & 0.5 \\
\hline & $M F R$ & 1 & 2 & 0.65 & 0.5 \\
\hline & $M F R$ & 1 & 2 & 0.35 & 0.35 \\
\hline
\end{tabular}

\section{Interaction}

4.1 Injection and Main Flow Streamlines

The interaction between injection and mian flow streamlines is shown in Fig. 10. Flow streamlines are colored by flow inlet source in the flow domain for the baseline and four test cases with four different injection blowing ratios. The white colored lines are representing the main flow streamlines starting from inlet section and the purple, blue, yellow, red and green streamlines are produced by the injected jets hole No. 1, 2, 3, 4 and 5 respectively, The lateral spreading of the traces on the blade span indicates the distance traveled by the jets, the level of consistency of injection, and the spanwise penetration by the jets, respectively, before they are mixed with the main flow, all of these are dependent factors on injection holes blowing ratio $M_{h \text {-inlet }}$. 


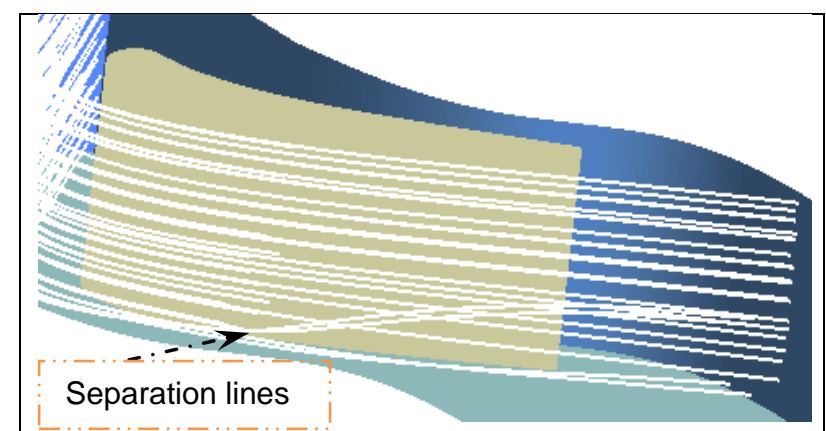

(a) Baseline case

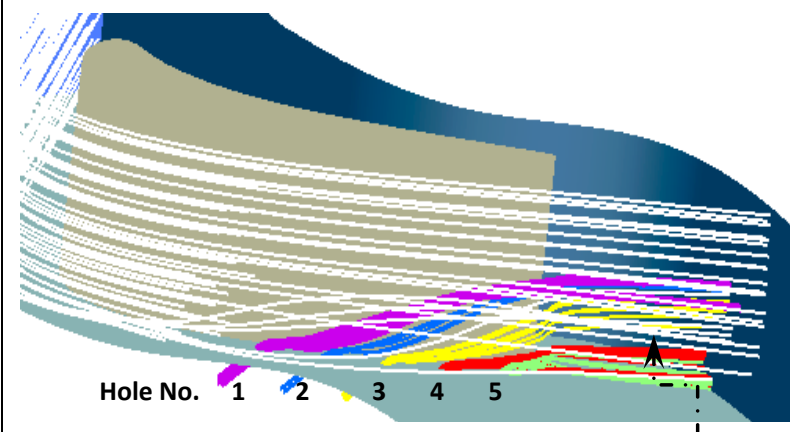

(b) $M_{h-\text { inlet }}=0.6$,

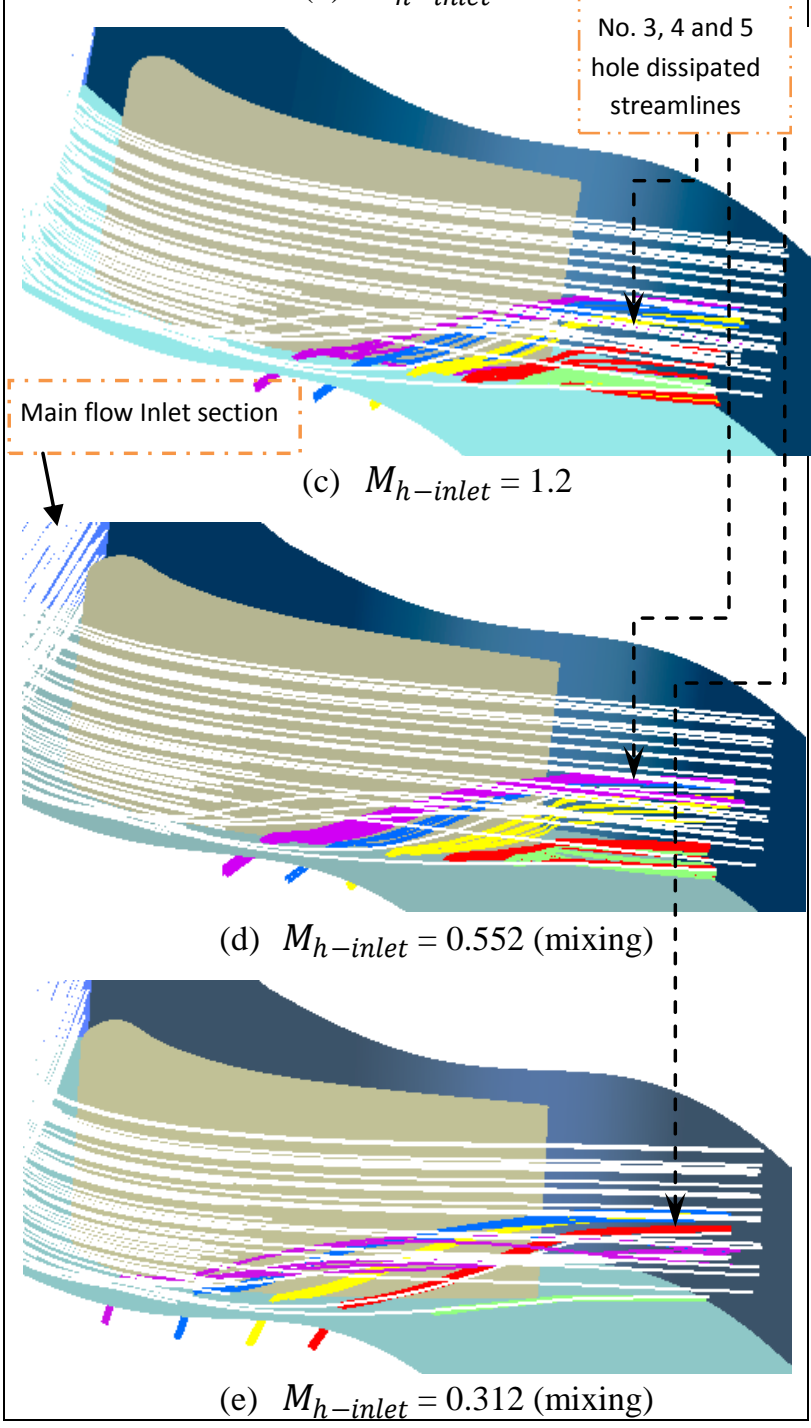

Fig. 10: Injection holes streamlines interaction with main flow streamlines with changing injection blowing ratio $M_{h-\text { inlet }}(\mathrm{a}, \mathrm{b}, \mathrm{c}, \mathrm{d}$ and $\mathrm{e})$
The main flow streamlines separation is clearly appeared at blade SS (suction side) as shown in Fig. 10 (a). The injection flow streamlines of hole No. 3 (yellow colored streamlines $)$ with blowing ratios, $\left(M_{h-\text { inlet }}=\right.$ 0.6 and $M_{h \text {-inlet }}=0.552$ (mixing holes MFR), can significantly dissipate in the main flow as indicated in Fig. 10 (b) and (d) compared to the same streamlines (yellow colored) with blowing ratios, $\left(M_{h \text {-inlet }}=1.2\right.$ and $M_{h \text {-inlet }}=0.312$ (mixing holes MFR) as shown in Fig. 10 (c) to (e). Thus, the main flow is more sensitive to dissipate these injection flow streamlines around blowing ratios $M_{h-\text { inlet }}=0.58$.

As indicated by red colored streamlines of the $4^{\text {th }}$ hole in Fig. 10 (e) is more penetrated deeply spanwise in the main flow comparing to the same red colored streamlines in Fig. 10 (c), which is more dissipated with main flow. Also, The fifth hole streamlines (green colored), is widely deflected downstream the blade TE with injection blowing ratios $M_{h-\text { inlet }}=0.312$ (mixing) as shown in Fig. 10 (e), which indicates an existence of weak injection flow from the fifth hole swept by the strong main flow.

\subsection{Static Pressure and Blade Loading}

By injection application, the pressure distribution does not change along most of the blade PS span or height except near blade T.E. with endwall corner, the static pressure on the blade SS increases slightly at the trailing edge due to the expansion at the trailing edge region.

As shown in Fig. 11 (a), due to the adverse pressure gradient on the suction, there is the potential of boundary layer separation from the suction-side blade surface near the trailing edge and this represents a major source of profile losses in the blade passage.

The injection flow effect is clearly notable in Fig. 11 (b) to (e), by increasing local static pressure at the blade SS as a result of the jet momentum spanwisely sweeping the pressure contours away from endwall. By injection with blowing ratios, $\mathrm{M}_{\mathrm{h} \text {-inlet }}=1.2$. Also, the low static pressure zone (blue colored) on blade SS is shrinking away from endwall and concentrated around blade mid span region as shown in Fig. 11 (b) to (e). Moreover, the area of relatively high pressure blade T. E. is increased by the effect of injection flow with blowing ratio $M_{h \text {-inlet }}=0.312$ as shown in Fig. 11 (e), comparing to other cases with injection.

The jet penetration effect is clearly seen in blade aft suction side with endwall corner by injection application with injection holes blowing ratio $M_{h \text {-inlet }}=0.6$ and $M_{h-\text { inlet }}-1.2$ as shown in Fig. 11 (b) and (c).

Results of blade loading ratio for base line and different injection blowing ratio $M_{h-\text { inlet }}$, are shown in Fig. 12. It indicates that, for all chosen injection blowing ratio $M_{h \text {-inlet }}$, there is an apparent increasing in blade loading comparing to baseline test case. As shown in Fig. 12, the maximum increasing in blade loading of $\mathrm{BLR} \%=1.85 \%$ can be obtained by injection application with injection blowing ratio $M_{h \text {-inlet }}=0.552$ (with mixing $\left.M F R_{h}\right)$. 


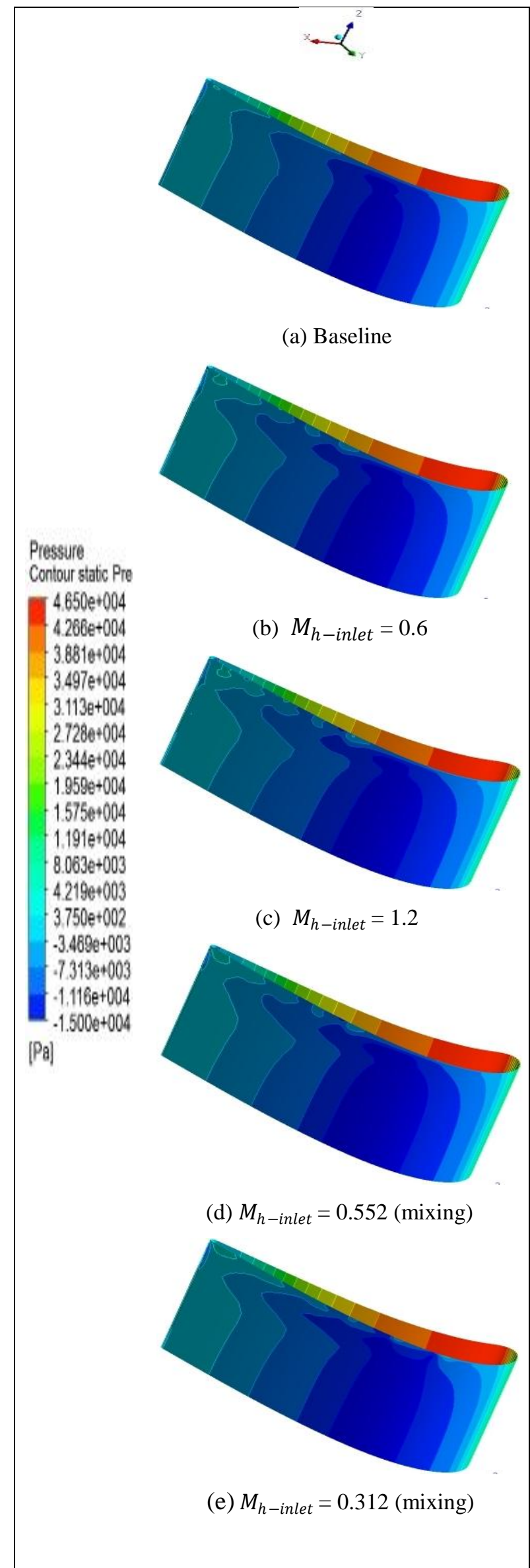

Fig. 11: Local static pressure on blade SS with changing injection blowing ratio $M_{h-\text { inlet }}(\mathbf{a}, \mathbf{b}, \mathbf{c}$, d and e)
And generally, Fig. 12 indicates that, the blade loading is increasing with the decreasing of blowing ratio from blowing ratio $M_{h \text {-inlet }}=1.2$ to 0.552 then blade loading relatively decreases with blowing ratio $M_{h-\text { inlet }}=0.312$, which indicates the weak level of mass flux of injection flow.

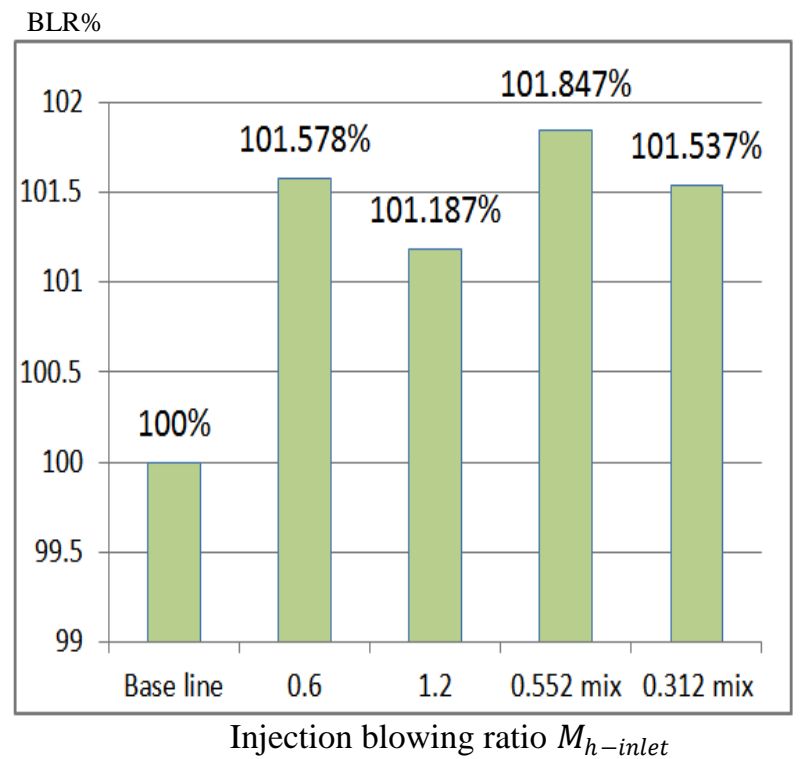

Fig. 12: Blade loading ratio (BLR \%) with changing injection blowing ratio $M_{h-i n l e t}$

\subsection{Exit Total Pressure and Losses}

Figure 13 represents the total pressure contours downstream blade TE $(108.6 \%$ axial chord) with changing the injection blowing ratio $M_{h-\text { inlet }}$ comparing to baseline test case. The peaks and valleys of pressure contours, at the endwall, locally decrease or increase the total pressure respectively. The high level of pressure loss in flow field is colored with deep blue. The secondary flows and the vortex can be clearly identified as low total pressure region.

Three main phenomenons can express the level of pressure losses in Fig. 13. First, the overall red to blue colors of the exit area which indicates the total pressure drop through the flow passage. Second, the bigger area of pressure contours core of the suction side leg vortex and the passage vortex, near the suction surface, indicates more pressure losses are created. The third phenomenon is the ratio of spanwise distance to blade span ratio $S_{z}$ of this core center to the endwall. Losses increase as this center moves nearer to the mid-span [1].

A high loss flow region appears on the suction side at the blade trailing edge, which is contributed by the secondary flow. In the baseline case as shown in Fig. 13 (a), a spanwise distance ratio of core center of the pressure contours to the endwall of $S_{Z}=17.5 \%$ is appeared.

Figure 13 (b) to (e) shows the total pressure loss distribution contour at the blade outlet with changing injection blowing ratio $M_{h-i n l e t}$. It could be seen that, the flow loss is reduced with injection blowing ratio $M_{h-\text { inlet }}=0.552$ as shown in Fig. 13 (c) with $S_{z}=19 \%$, but the blue area of pressure contours core is increased. 


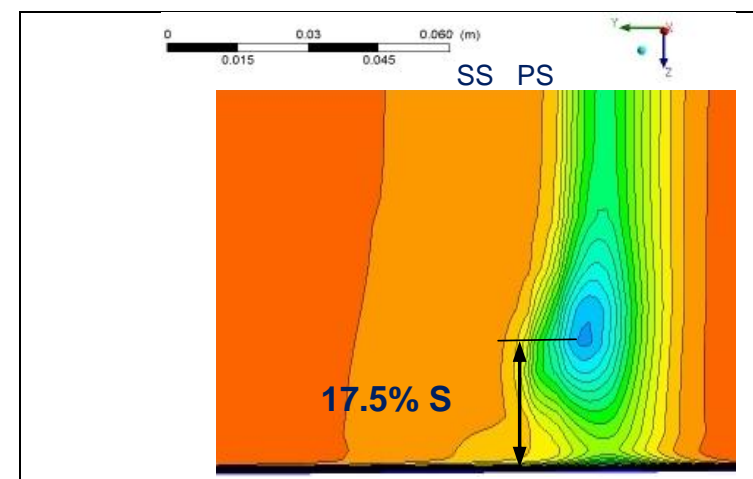

(a) Baseline

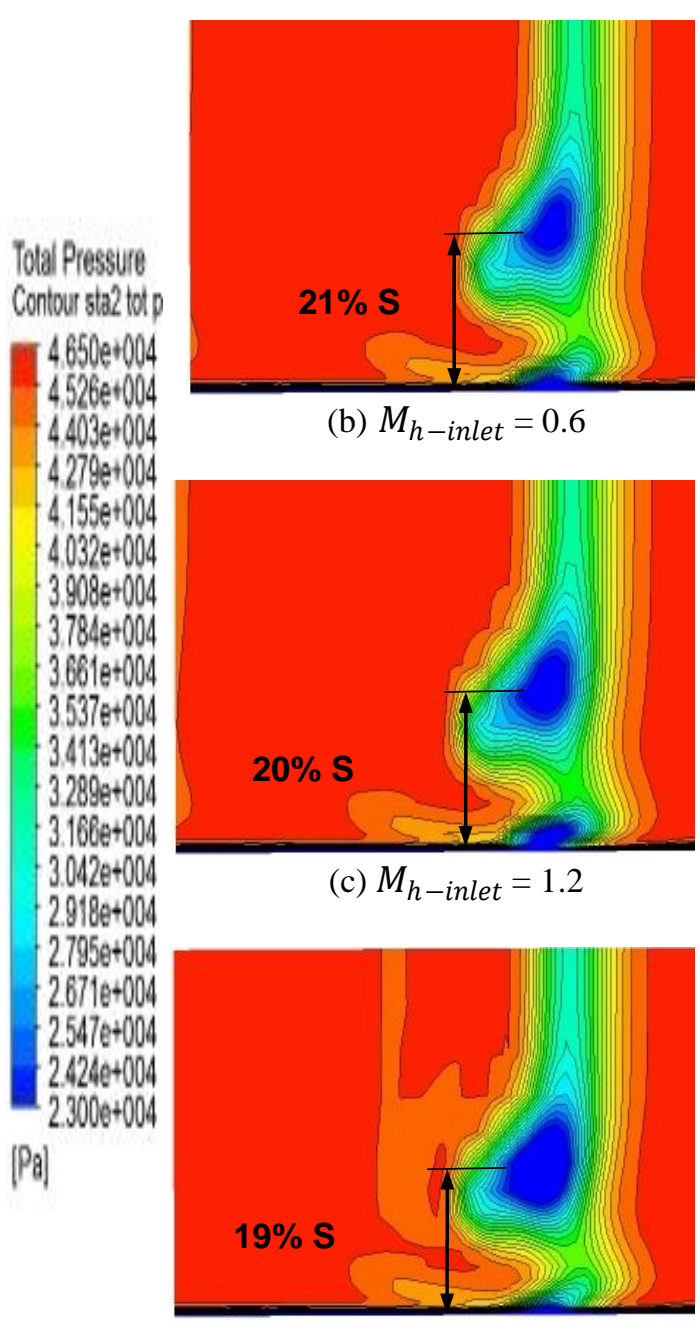

(d) $M_{h-\text { inlet }}=0.552$ (mixing)

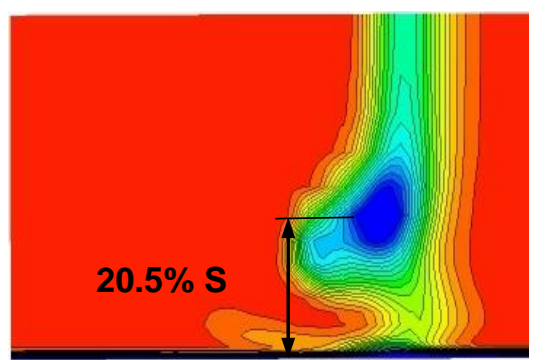

(e) $M_{h-\text { inlet }}=0.312$ (mixing)

Fig. 13: Total pressure contours downstream blade T. E. (108.6\% axial chord with changing injection blowing ratio $M_{h \text {-inlet }}(\mathbf{a}, \mathbf{b}, \mathbf{c}, \mathbf{d}$ and $\mathbf{e})$
Also, Fig. 13 (b) shows a relatively smaller area of pressure contours core by injection blowing ratio $M_{h-\text { inlet }}=0.6$, while the spanwise distance ratio of pressure contours core center to blade span is $S_{Z}=21 \%$.

By injection with blowing ratio $M_{h-\text { inlet }}=0.312$, a notable reduction of pressure contours core area is shown in Fig. 13 (e) while the spanwise distance ratio of pressure contours core center to blade span is $S_{z}=$ $20.5 \%$.

Comparisons of the baseline case results Fig. 13 (a) to the injection cases at blade SS with changing injection holes blowing ratio $\beta_{h}$ Fig. 13 (b) to (e), indicate that, the injection flow changes the secondary flow to keep the passage vortex close to the endwall and by reducing the depth of the associated loss core as shown in Fig. 13 (c) and (d). Injection at by blowing ratio $M_{h \text {-inlet }}=$ 0.552 seems to produce bigger area of pressure contour core and thicken the exit boundary layer and gives a strong indication that, this injection can significantly increase the secondary losses.

The results introduce that, this injection location at blade SS, reduces the total pressure loss across the blade passage by weakening the endwall cross flows and passage vortex, and hence the location chosen for injection is very important in this respect. Fig. 13 shows the great difference of pressure field and provides evidence by how strongly the main flow deflect some jets flow because of their injection holes blowing ratio $M_{h-\text { inlet }}$.

The length of the traces, the level of blue color and the lateral spreading of the traces indicate the distance traveled by the jets, the level of consistency of injection, and the spanwise penetration by the jets, respectively, before they are mixed with the main flow, all of these are dependent factors on injection holes blowing ratio $M_{h-i n l e t}$. By checking the results carefully, it is clear that the injection holes blowing ratio $M_{h \text {-inlet }}=0.312$ is more effective to suppress the secondary flow loss near the end-wall with $S_{z}=20.5 \%$ with relatively smaller contours core area as shown in Fig. 13 (e).

The injection blowing ratio $M_{h-\text { inlet }}=0.6$, is more effective to suppress the secondary flow than higher blowing ratio, $M_{h-\text { inlet }}=1.2$, as seen in Fig. 13 (b) and (c). While, Fig. 13 (d) shows that, the injection with blowing ratio $M_{h \text {-inlet }}=0.552$ (with mixing $M F R_{h}$ ), leads to increasing the concentrated region of loss with the growth in the depth of the main loss cores far from the endwall.

Figure 14 represents the change of exit total pressure loss coefficient with different injection blowing ratio. It could be thought that the injection flow with injection blowing ratio $M_{h \text {-inlet }}=0.312$ (with mixing $M F R_{h}$ ), is more effective methods to suppress secondary flow development in a maximum loss reduction obtained in this investigation, about $2.1 \%$, comparing to the baseline test case, which consider the best result in loss reduction. Moreover, the mixing mechanism of injection flow in this test case minimizes the low pressure contours core area and relatively decrease spanwise core distance to endwall. 
$\omega \%$

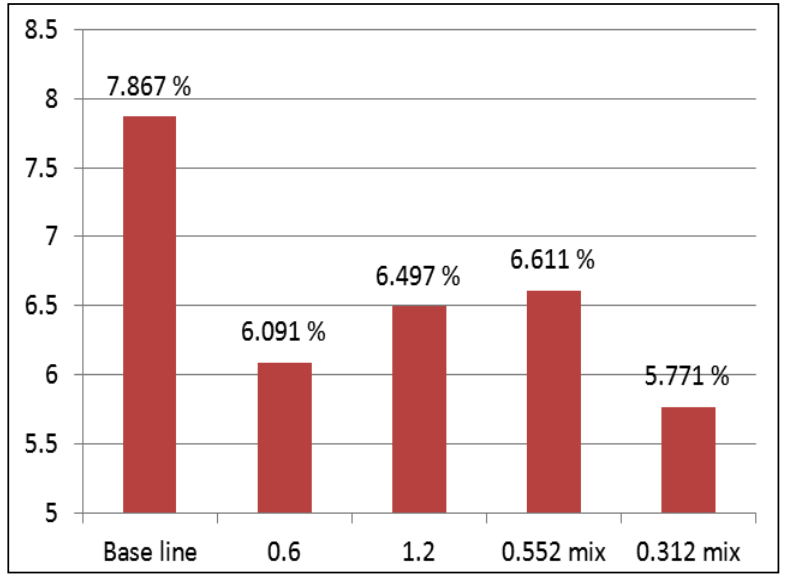

Injections blowing ratio $M_{h-\text { inlet }}$

\section{Fig. 14: Total pressure loss coefficient $\omega \%$ with changing injection blowing ratio $M_{h-\text { inlet }}$}

The pressure loss is decreased by $1.25 \%$ compared to baseline case, by injection blowing ratio $M_{h-i n l e t}=$ 0.552, as shown in Fig. 14. As it can be seen, the secondary loss reduction is almost same when the jets flow with injection blowing ratio $M_{h-\text { inlet }}=1.2$ and with injection blowing ratio $M_{h \text {-inlet }}=0.552$ with mixing $M F R_{h}$ for each individual injection hole, which indicates this mixing mechanism strengthen the secondary flow harmful effect on main flow.

\section{ECONOMIC REVIEW}

The aviation fuel consumption is of a great concern, which worries commercial airlines. Nowadays, the daily worldwide jet fuel consumption is about 5.6 million barrels per day, or 5.8 percent of total global oil consumption and the demand for fuel could increase by as much as 2.7 million more barrels per day by 2030 , OPEC [19]. This may make the achieved result of $2 \%$ in the current study, either loss reduction or gain in blade loading, leads to a jet fuel consumption reduction of 41 million barrel per year or a jet fuel cost reduction of 3.2 billion US\$ per year (with averaged 2018 jet fuel barrel price of 87.3 US\$), IATA [20], which can consider a valuable achievement in the aviation industry. This is only in the field of aviation, not to mention the fuel saving in other land uses of the gas turbine engine. In addition to decrease carbon emissions rate to keep clean atmosphere.

\section{CONCLUSIONS}

The important conclusions can be drawn from this thesis are:

1- Endwall jets located towards the suction side of a turbine blade passage were effective in altering the path of the pressure-side leg of the corresponding blade horse shoe vortex and leads to improve the mixing of control flow and main flow separation and hence produce increasing in static local pressure on pressure side
(1.85\% increasing in blade loading) comparing to the base line case and hence saving more power for turbine rotation.

2- The blade loading has not a linear relation with injection blowing ratio and an existence of inflation blowing ratio is exist with value around $M_{h \text {-inlet }}=$ 0.552 , the blade loading reverse its influence with blowing ratio, as shown in Fig. 9.

3- The total pressure loss does not react in a linear relation with injection blowing ratio and an existence of inflation blowing ratio is exist, with value around $M_{h \text {-inlet }}=0.552$, where the flow reverse its influence with flow losses, as shown in Fig. 11.

4- the new injection arrangement technique has proved its effectiveness in suppressing total pressure losses by loss reduction of $2.1 \%$ less than baseline test case and that is implemented by individual change for each hole injection hole mass flow rate, as in test case with mixing blowing ratio $M_{h \text {-inlet }}=0.312$ with injection location at blade SS. This case can be applied on turbojet engine design while the fluid energy is a higher priority aspect in engine design.

5- The blade loading and flow losses are changing independently with injection parameters change, i.e. the increasing in the blade loading, for certain injection arrangement, does not reflect a reduction in flow losses. The test case of blowing ratio $M_{h-\text { inlet }}=0.6$ with mixing MFR has the best simultaneously results for both two important flow factors and both cases can be applied on turbofan engine design, while mechanical and fluid energies are simultaneously required.

6- The new injection arrangement technique has proved its effectiveness in increasing blade loading $1.85 \%$ comparing to baseline test case, and that is implemented by individual change for each hole mass flow rate as in test case with blowing ratio $M_{h \text {-inlet }}=0.552$, with injection location at blade aft half SS. This case can be applied on turboshaft or turboprop engine design, while the mechanical energy is a higher priority aspect in engine design.

7- All selected test cases gave positive different readings with respect to blade loading and loss reduction, comparing to baseline test case, which proves the great effectiveness of injection location at blade SS on increasing blade loading.

8- The injection flow, in most of test cases, was deflected and dissipated because of high inlet pressure boundary conditions of basically selected experimental test case to validate and study.

\section{NOMENCLATURE}

C $\quad$ Blade chord [m]

$C_{a x} \quad$ Blade axial chord $[\mathrm{m}]$

$C_{L} \quad$ Lift coefficient $C_{L}=2 \mathrm{~L} / \rho A v^{2}$

$C_{P S} \quad$ Static pressure coefficient $C_{P s}=\left(P-\overline{P_{2}}\right) /\left(P_{t 1}-\overline{P_{2}}\right)$

$C_{P t} \quad$ Total pressure coefficient $C_{P t}=\left(P_{t 1}-P_{t}\right) /\left(P_{t 1}-\overline{P_{2}}\right)$

$D_{h} \quad$ Injection hole diameter [m]

$i \quad$ Incidence angle [deg], $i=\beta_{1}-\beta_{1, \text { des }}$ 
$k \quad$ Turbulent kinetic energy per unit of mass

[Joule/kg], $k=\frac{1}{2}\left(u^{2}+v^{2}+w^{2}\right)$

$\dot{\mathrm{m}} \quad$ Mass flow, $\mathrm{kg} / \mathrm{s}$

$M \quad$ Mach number

$M_{h-\text { inlet }}$ Blowing ratio,

$M_{h-\text { inlet }}=\left(\dot{\mathrm{m}}_{\text {inj }} / A_{\text {holes }}\right) / \rho_{\infty} . U_{\infty}$

PR Pressure Ratio, $\mathrm{PR}=P_{t 1} / \overline{P_{2}}$

$\mathrm{P} \quad$ Pressure [Pa]

$\bar{P} \quad$ Area-averaged static-pressure [Pa]

$\bar{P}_{t} \quad$ Area-averaged total-pressure [Pa]

Re Reynolds number, $\operatorname{Re}=\rho U_{1} C_{a x} / \mu$

$S_{z} \quad$ The ratio percentage of spanwise distance to the blade endwall relative to blade span, $S_{z}=\frac{z}{S} * 100 \%$

$u \quad$ Velocity at $\mathrm{x}-$ coordinate $\left[\mathrm{m} \mathrm{s}^{-1}\right]$

$\mathrm{U} \quad$ Total velocity $\left[\mathrm{m} \mathrm{s}^{-1}\right]$

$v \quad$ Velocity at $\mathrm{y}-$ coordinate $\left[\mathrm{m} \mathrm{s}^{-1}\right]$

$\mathrm{V} \quad$ Volume flow rate, $\mathrm{m}^{3} / \mathrm{sec}$

$w \quad$ Velocity at $\mathrm{z}-$ coordinate $\left[\mathrm{m} \mathrm{s}^{-1}\right]$

$x \quad$ Chordwise (axial) coordinate

$y \quad$ Pitchwise coordinate

$z \quad$ Spanwise coordinate

$y^{+} \quad$ Dimensionless wall distance (y plus), $y^{+}=\frac{u_{T} \cdot y}{v}$

\section{Subscripts}

$\begin{array}{ll}1 & \text { Cascade inlet value } \\ 2 & \text { Cascade exit value } \\ \text { ax } & \text { Axial } \\ \text { des } & \text { Design value } \\ h & \text { Injection hole } \\ \text { holes } & \text { All injection holes } \\ \text { i } & \text { Isentropic value } \\ \text { in } & \text { Inlet } \\ \text { inj } & \text { Injection flow } \\ \text { out } & \text { Outlet } \\ \mathrm{s} & \text { Static conditions } \\ \mathrm{t} & \text { Total conditions } \\ \infty & \text { Mainstream air at inlet conditions } \\ 1,2 . ., 5 & \text { Injection hole number }\end{array}$

\section{Greek symbols}

$\alpha_{h} \quad$ Injection hole orientation angle

$\beta \quad$ Relative flow angle [deg]

$\beta_{h} \quad$ Injection hole blowing ratio

$\mu \quad$ First (dynamic) viscosity [Pa.s]

$\rho \quad$ Density $\left[\mathrm{kg} / \mathrm{m}^{3}\right]$

$\omega \quad$ Loss coefficient,

$$
\omega=\left(P_{t 1}-\overline{P_{t 2}}\right) /\left(P_{t 1}-\overline{P_{2}}\right)
$$

\section{Abbreviations}

$\begin{array}{ll}\text { 2D } & \text { Two Dimensions } \\ \text { 3D } & \text { Three Dimensions } \\ \text { AR } & \begin{array}{l}\text { Area Ratio, injection hole area outlet to area } \\ \text { inlet }\left(A_{\text {out }} / A_{\text {in }}\right)\end{array} \\ & \text { Blade Loading Ratio }\left(\frac{L .}{L_{\text {baseline }}} \cdot 100 \%\right) \\ \text { BLR\% } & \text { Computational Fluid Dynamics } \\ \text { CFD } & \text { Energy Efficient Engine } \\ \text { EEE } & \text { Experiment }\end{array}$

GE- $E^{3} \quad$ General Electric - Energy Efficient Engine

HPT High Pressure Turbine

IATA International Air Transport Association

LCTR Large Civil Tilt Rotor

L.E. Leading Edge

MFR Mass Flow Rate

OPEC Organization of the Petroleum Exporting Countries

SA Spalart-Allmaras

SS Suction Surface

STA2 Station at Passage flow Exit section

T.E. Trailing Edge

\section{REFERENCES}

1- Acharya S. and Mahmood G. "Gas Turbine Hand Book- sec. 4.3 Turbine blade aerodynamics" A Handbook of Land, Sea and Air Applications by Claire Soares, publisher Butterworth Heinemann, BH, McGraw Hill, (2006).

2- Gregory-Smith D. G. and Okan B. M. 'The Estimation of Secondary Flows and Losses in Turbines", Proceedings of 1st European Turbomachinery Conference - Fluid Dynamic and Thermodynamic Aspects, Germany. (1995).

3- Langston L.S. "Crossflows in a turbine cascade passage" ASME Journal Engineering. Power, 102 (4), pp. 866-874. (1980).

4- Denton J.D. and Cumpsty N.A. "Loss mechanisms in turbomachines"; Institue of Mechanical Engineers; Paper No.: C260/87, (1987).

5- Sharma, O. P., Joslyn, H. D. \& Dring, R. P. "Redistribution of an inlet temperature distortion in an axial flow turbine stage", AIAA J. Propulsion and Power Vol. 5(No. 1): 64-71. (1989).

6- Dixon S.L., Hall C.A. "Fluid Mechanics and Thermodynamics of Turbomachinery" 6th Edition. Burlington: Elsevier Inc., (2010).

7- Satta F. and Tanda G. "Effect of discrete-hole arrangement on film-cooling effectiveness for the endwall of a turbine blade cascade" Applied Thermal Engineering 91, 507e514. Genova, Italy, (2015).

8- Leylek J. H. and Zerkle R. D. "Discrete-Jet Film Cooling: A Comparison of Computational Results with Experiments," ASME Journal of Turbomachinery, Vol. 116, pp. 358-368, (1994).

9- Kamil Abdullah, Haswira Hassan and Muzzammil Pauzi "Effect of density ratio on the performance of purge flow in linear cascade arrangement" International Research and Innovation Summit (IRIS2017), IOP Conf. Ser., Mater. Sci. Eng. 226 012151, (2017).

10- Tyler Rice "Numerical analysis of the film cooling effectiveness on a highly loaded low pressure turbine blade in conjunction with endwall effects" MSc. Thesis, Texas A\&M University, (2017)

11- Ashlie B. McVetta, Paul W. Giel and Gerard E. Welch "Aerodynamic Investigation of Incidence Angle Effects in a Large Scale Transonic Turbine Cascade"NASA/TM-2013-218070/REV1, (2014). 
12- Timko L. P., "Energy Efficient Engine High Pressure Turbine Component Test Performance Report," NASA/CR-1984-168289, (1984).

13- Alam El-Din A. M. , El-Sawaf I. A. , El-Abady A. A. , Hassan Y. K. "An Investigation of the Controlling Methods for the Secondary Losses in Turbine Blades" The Research Journal of Shebin El-kom Faculty of Engineering, Minoufiya University, Vol. 34 No.2 (April 2011).

14- "ANSYS FLUENT Theory Guide" ANSYS, Inc., www.ansys.com, Release 14.5, (2013).

15- Versteeg H.K., Malalasekera W. "An Introduction to Computational Fluid Dynamics The Finite Volume Method" Pearson Education Limited, Glasgow,2nd edition, (2007).

16- Wan Aizon W Ghopa, Zambri Harun, Ken-ichi F. and Takemitsu M. "Aero-Thermal Performances of Leakage Flows Injection from the Endwall Slot in Linear Cascade of High-Pressure Turbine" Journal of Thermal Science Vol.24, No.1, (2015).

17- Theodore von Kármán,"Mechanical Similitude and Turbulence" Tech. Mem. NACA, no.: 611, (1931).

18- Goldstein R. J. and Spores R. A. "Turbulent Transport on the Endwall in the Region Between Adjacent Turbine Blades" ASME Journal of heat transfer Vol 110, (1988).

19- OPEC, Monthly Oil Market Report, 13 November (2018).

20- IATA, Jet fuel price monitor publication, www.iata.org/publications/economics/fuelmonitor/Pages/index.aspx, (December 2018).

21- Alam El-Din A. M., El-Ghandour M. E., Hassan Y. K. "A Numerical Study on the Effect of Air Injection on Secondary Flow in a Turbine Cascade" A Doctorate Thesis, Faculty of Engineering, Port Said University, Egypt (2018).
دراسة رقمية لتأثير تغيير نسبة نفخ حقن جدارى على أداء

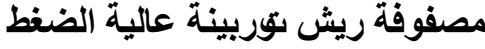

$$
\text { ملخص البحث }
$$

يتجناول هذا البحث دراسة رقمية لمحاكاة التحكم فى المفاقيد الثنانوية

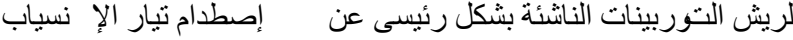

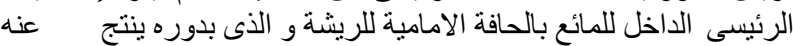

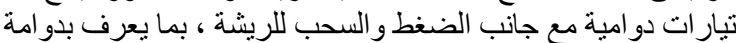

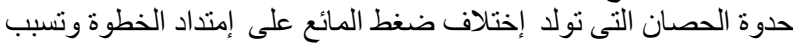

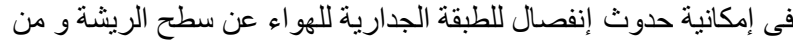

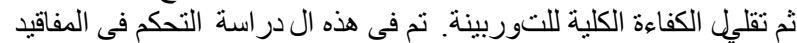

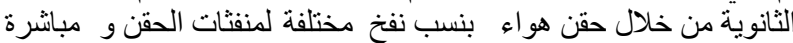

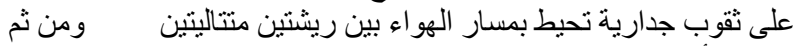

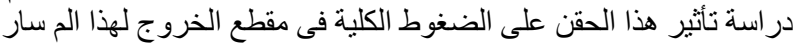

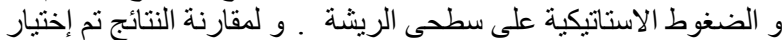

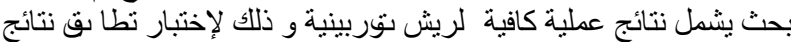

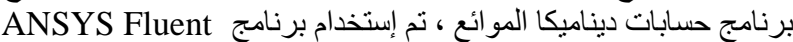

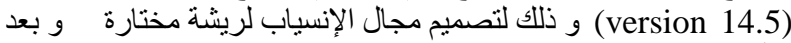

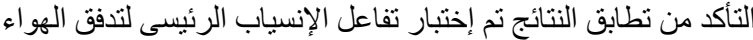

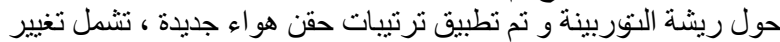

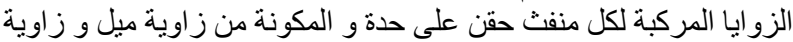

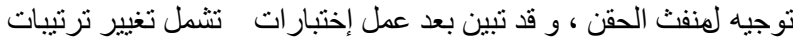

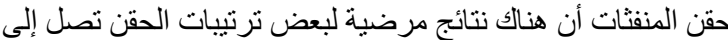

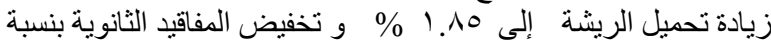

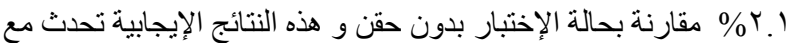

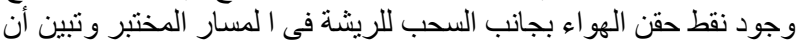

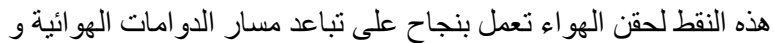

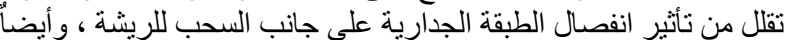

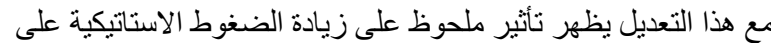

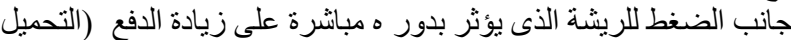

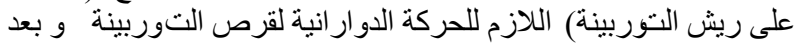

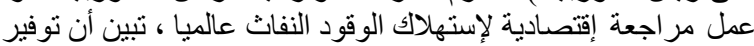

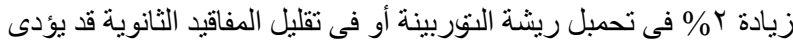

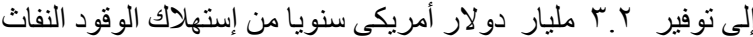

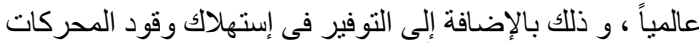

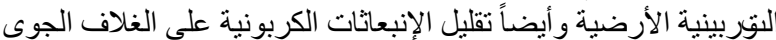

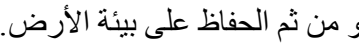

